\title{
The dawn of Lean marketing
}

\author{
Roy Dewell \\ is the Managing Consultant for PIPC's Lean Marketing Practice and Editor of www.mrm-explained.com. He has experience of \\ over 40 DAM and MRM implementations including the total MRM implementation at Scottish Enterprise. He is currently involved \\ in marketing system implementations in the UK, Canada, Switzerland and Sweden. PIPC is a leading project and programme \\ management company operating globally from 11 offices. PIPC is currently helping both MOM/DAM systems vendors and our \\ own clients to achieve significant operational benefit by adopting our Lean Marketing principle.
}

Keywords: lean, marketing, benefits, MRM, EMM, change

Abstract Lean systems is a well-established methodology for reducing waste, increasing efficiency and increasing the professionalism of the people employed. In this paper, the author argues that marketing is poised to move from implementing individual systems such as DAM or marketing segmentation towards managing the whole of marketing along Lean principles. He believes that the growing number of successful case studies, plus pressures created by increases in Below The Line marketing, demands for regulatory compliance as well as the demands on CMOs to deliver better reporting are major driving forces. Surveys show that significant numbers of companies intend to make this move by the end of 2007, while at the same time the leading marketing systems vendors are announcing products which now are directed at total marketing.

Journal of Digital Asset Management (2007) 3, 23-28. doi:10.1057/palgrave.dam.3650054

\section{THE HISTORY OF LEAN}

Lean systems can be traced back to the Toyota Production System (TPS) devised by Sakichi Toyoda, his son Kuchiro Toyoda (founder of the Toyota Motor Corporation) and the engineer Taiichi Ohno. They were so driven by their desire to reduce waste (Munda) and eliminate unnecessary production steps that they devised the TPS continuous and systematic approach to improve their manufacturing processes.

The term Lean Manufacturing is attributed to Womak and Jones. They first named and described the process in 1991 in their book "The Machine that changed the World," which detailed their research into the world's automotive industries (including Toyota). This was further refined in their book "Lean Thinking" 2 which was first published in 1998.

Since that time other similar systems and Roy Dewe 12 Appold Street, London EC2A $2 \mathrm{AW}$, UK Tel: +44 (0) 2071335999 Fax: +44 (0) 2071331029 Email: roy.dewell@pipc. com such as Value Engineering (VE), Crosby Total Quality Management (TQM) and more recently Six Sigma, ${ }^{3}$ but Lean systems remains the most widely used. variations have been developed and promoted,
Although there are defined tool sets to use and procedures to follow to be "authentically" Lean, over the last few years the term has passed into the global consciousness in the same way as the global acceptance of "hoover" (ie people buying a vacuum cleaner will often ask for a hoover and expect to see a range of brands not just Hoover). So much so that the leading official Lean blog $^{4}$ avoids all of the technical points stating:

"One way of defining Lean has two parts:

1. Eliminate waste and non-value-activity (NVA).

2. Have respect for people".

The respect for people is further explained as

"Respect means you hold people accountable to the system, following it and improving it (the notion of 'kaizen' or continuous improvement). Lean leadership is about enabling and empowering people. Lean leadership is about helping people grow professionally and personally, allowing them to take pride in their work". 


\section{LEAN AND MARKETING}

What has all this got to do with what is happening to marketing? If you read most of the output from Consultants and Systems Houses on marketing, the emphasis is all on MOM, MRM, MAM, EMM, e-channel communications or just extending the DAM. From this you would surmise that marketing is still in the infancy stage of improvement where system acronyms seem to be the goal and few people are taking a holistic view of the entire marketing process.

Well, over the last few months I have noticed a subtle change in the messages from marketing departments about their experiences and expectations from marketing systems.

Our research show us that there is a fundamental change in the attitude of the marketing department away from a focus on individual IT systems, and onto an enterprise wide view of the marketing function and its associated processes. This focus on Lean processes has already had a dramatic impact in other areas of the company and marketing will benefit from that experience as they approach the dawn of Lean marketing.

In this paper, I use the term Lean marketing to mean a systematic continuous improvement process that will eliminate waste and inefficient processes, speed up production cycles and increase the professionalism of the people in every aspect of marketing. The emphasis is very much on process and procedure with supporting technology, rather than technology led functionality improvement.

The changing messages from marketing have been presented in papers, at conferences and anecdotally at meetings with current and potential customers. The research is based upon findings from leading authorities which have been published in the public domain, surveys completed by PIPC, ${ }^{5}$ while the knowledge of the emerging technologies comes from seeing pre-releases and, in some cases, new releases of product from suppliers.

\section{CURRENT LEAN MARKETING SYSTEMS}

Until recently only two areas of marketing had been subjected to a rigorous process of continuous improvement. These are the DAM and the customer segmentation/analytics area. This is because in both these areas the processes and practices needed to reduce waste and deliver more for less to shorter time scales are well understood. There is ample software to deliver the required functionality and most significantly, there are a growing number of case studies showing how by changing some processes and applying the correct principles companies saved time and money and delivered significant other benefits. Both these areas are now, in the more successful instances, managed within the company's marketing community by people who fully understand what is needed to be done and are empowered to deliver the service. Additionally, as with other Lean initiatives, these departments have not just implemented a system, they have started a continuous and permanent process of systems improvement which will deliver more and different benefits as their businesses change or they develop more skills.

For the DAM, objects are stored in a central repository which records the rights to use, etc, while metadata define the objects so that they can easily be retrieved by the right people. Items are stored in their native format so they can be reused or amended without any loss of quality. In good systems, software handles network/ bandwidth issues so people can view or work with large files without causing major traumas for other network users. The system will have automated workflow so that the right files are used by the printers while appropriate security ensures the rights to view or use are restricted to authorized people. Substantial time and risk will have been taken out of the production cycle. In really efficient instances print may be delivered on a just-in-time basis that minimizes stock holdings and makes sure collateral is available at the right time. Over time standards and records of print costs, etc will have been developed so that the level of savings will be maintained, competitive procurement can be developed and the days of department " $x$ " giving large jobs to printers or agencies which are in dispute with department " $y$ " should be numbered.

Two key features of DAM technology are the configurability of the system and the way they can be managed by people who do not require in-depth technical knowledge. 
First, there is sufficient freedom allowed in most DAM systems so that companies are not constrained by the one size fits all model. The systems allow the storage hierarchy, metadata and workflow to be configured in a way which is specific to the requirements of each company. This is delivered while still supporting the right practices and procedures to make sure the sanctity of the original image is not compromised and metadata appropriate to the company and its method of trading are enforced.

Secondly, as in all Lean systems, it increases the professionalism of the people operating the DAM. With a DAM, marketing people take on the responsibility for the operational management of the company's collateral rather than merely paying a repro-house to perform all the tasks.

The capability of using the DAM to significantly improve most aspects of work using company assets is here now. Although not every company achieves all the benefits the way forward is clear and signposted. Companies which have introduced DAMs have an operational and hence commercial advantage compared to the laggards which may still store images in different formats across different repro-houses. The time is not so far off, in fact it may be upon us, that this advantage will become so self-evident that DAMs will become the next must-have technology just to keep pace.

Customer segmentation is at a similar level of maturity. The underlying principles are equally understood. If you can direct your marketing message to the right potential customer for your product, then you eliminate the need for ineffective mass mailings saving costs on mailing and collateral. More significantly, the right message to the right potential customer should lift sales. Again, as with DAM technology there are multiple suppliers offering variations on a theme that will deliver what you want. People argue that selection should be product-oriented or customer-centric or geographic or driven by spending power or age. In no way do I try to devalue any of these cases or to hold that one approach is more universally correct than all the others. The point is that the software offers the flexibility for different companies to make their own appropriate selections and to vary the selections when they think it is appropriate. The software is very clever. Increasingly systems can select records from wider varieties of file formats and can perform complex associations to find the records. For example, I may be looking to mail high earners in the south east of England, but the main file I will access may not have salary details. It does, however, hold addresses and ages as well as an indicator to show employment status. I could, with a reasonable degree of certainty, extract my high earners if I select people under 60, with a current mortgage, who are in full-time employment, who live at addresses which are in council tax band A. This may involve making selections from more than one file, but good segmentation systems will support this. As with the DAM the process and procedures to follow are fully understood. The systems are run within the company, by empowered marketing staff. The systems do not enforce one size fits all, so the different companies can select their customer segments based upon characteristics that are specific to their requirements.

There are many case studies which prove that using these systems saves money, time and delivers significant benefit. Again not every company is using the system as effectively as possible but the way forward is unambiguous. Market segmentation is already a key technology that is accepted and is professionally managed within marketing.

Both these areas have shown that aspects of marketing which at one time were regarded as the domain of specialists can be managed in-house by marketing staff when supported by the right IT systems and processes. This can deliver major cost savings and benefits to the company without any loss of quality. At one time it would have been unthinkable for a marketing department to manage the storage and reformatting of JPG or Quark files without the continuous involvement of a repro-house but now such things are routine. There are ample case studies ${ }^{6}$ quoting savings in costs, time and other substantial benefits for growing numbers of companies. As a result, departments can implement these technologies without having to be system pioneers. These experiences have emboldened marketing so that they are ready to take on other aspects of marketing that are currently provided mainly by external agencies. 


\section{EVIDENCE OF THE MOVE TO LEAN}

DAM and marketing segmentation are only two of the departments within marketing and involve only a small percentage of the marketing staff. The remainder of marketing appears currently to be untouched and is referred to in most presentations as the "last bastion of manual work within the enterprise." Diagram 1 below gives some indication as to the variety of different tasks completed within marketing.

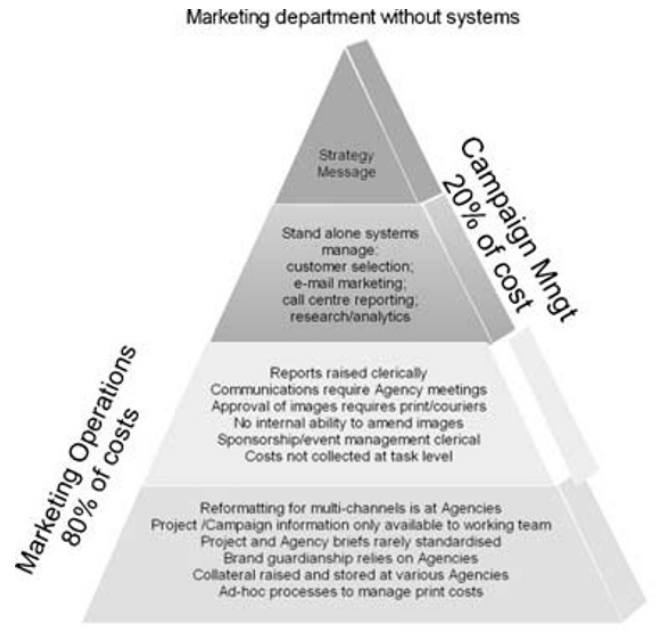

While it is currently true that most marketing departments do not run total control systems, research shows that this may soon be about to change. In the PIPC survey ${ }^{5}$ run in May 2006, although only 4 per cent of companies reported that they currently run over all management systems, 59 per cent reported that they have or are researching the systems available and 64 per cent reported that they propose to have something implemented by the end of 2007. Further, at the Amsterdam MOM/DAM symposium $^{7}$ there were a number of case studies from companies which have, or are in the processes of implementing control systems for managing large parts of their marketing. Most of the companies presenting reported that the largest issues they faced were people and processes, not short fallings in the technology. This is because to achieve the change they not only have to change process they have to empower their staff to take on roles and responsibilities that are currently managed externally at agencies. The people presenting reported technology as an enabler and never reported any lack of suitable technology.

The companies presenting may be ahead of the game, but they are a clear indication of what is emerging. This was further demonstrated by a Panel discussion on the Evolution of Client/ Agency relationships. Agencies are aware of the developing changes and, in my view, the smart ones, are adapting in preparation. One of the Panel speakers was from Magnet Harlequin ${ }^{8}$, a marketing communications and brand production services company that has developed their own marketing management software which they run for their clients. Clients using their software can manage most of their processes without needing to use the repro or design services of Magnet Harlequin. Magnet Harlequin have spend considerable time effort and money on developing this system as they believe the move to more automated marketing run by marketing is inevitable.

At the Amsterdam Symposium in their presentation on Strategic Marketing Performance, Management Accenture reported that average cost savings of $8-25$ per cent with revenue enhancement of 3-8 per cent are routinely possible when systems were applied across the whole of marketing. These are considerable sums and go a long way to explaining why pay back of marketing systems is normally within two years.

\section{FACTORS INFLUENCING THE MOVE TO LEAN}

Research has also highlighted other factors that are influencing the move towards systems managing the total marketing operation.

It is an accepted truth that Below The Line marketing (BTL) delivering personalized messages directed at specific sectors of the market is the most effective way to communicate with the required audience. Budget research by the Winterberry group ${ }^{9}$ shows that BTL spending is increasing by an average of 7.8 per cent each year. This is borne out by the PIPC survey ${ }^{5}$ in which the largest single reason for increases in budget was reported to be BTL marketing. From a workload point of view BTL marketing creates significant demands on the department. Instead of completing say one advert in a national paper 
BTL may require five individual adverts in specific interest magazines supported by five tailored mailshots that will be different to reflect the particular interests of the prospective customers. Although the budgets for BTL have grown, very few companies have budgeted for increases in staff (based on responses to PIPC survey ${ }^{5}$ ), or for the significant extra costs which BTL will incur (eg print runs for different brochures will be smaller so printing costs will rise). So many departments struggle to find ways to absorb the work and costs.

Legislation across Europe and the USA requires that marketing manages regulatory compliance across all the collateral they produce. For example, this may be a Financial Services Authority requirement that interest rates are shown according to a pre-defined formula, requirements from the Food Standards Agency that the presence of GM ingredients is clearly listed or the Sarbanes-Oxley requirements that marketing processes are transparent and appropriately documented. In these instances it is no longer sufficient to rely upon the repro-house or agency as the main guardian of compliance. What is needed is a total approach to marketing whereby procedures within the department guarantee and audit compliance. In several surveys this is reported as a major concern for CMOs, particularly those that must rely on clerical procedures to enforce the compliance.

It is an oft repeated statistic that the employment span of a CMO is now less than two years, The reasons given for this vary across the different agencies, often depending upon the services they are promoting. ${ }^{10}$ But frequently cited reasons include the increasing complexity of the role, the need to be able to swiftly and flexibly respond to changes across the multiple channels to market and problems in the financial area where calculating ROI seems to require support which is not present in most marketing departments. All of these points are problems for the marketing department that is the last bastion of manual labor.

Fortunately, new technology offerings are emerging from the leading marketing systems suppliers. Aprimo ${ }^{11}$ have recently announced and shown their role-based solution built upon service-oriented architecture which provides far more functionality than was previously available from products aimed at the MRM sector.
Equally Assetlink ${ }^{12}$ have shown pre-releases of their role-based solution which moves them away from being just a Marketing Operations supplier. And new companies of substance are entering the market. Alterian, ${ }^{13}$ a marketing analytics and campaign management company has bought Nvigorate, ${ }^{14}$ an MRM company and are planning to extend the joint offering from the combined Alterian and Nvigorate product sets.

And now the CMO sees a growing list of companies which have successfully started to use systems ranging across DAM and MRM, faces demands to complete more work while supporting compliance, without the option of increasing staff, and is offered a growing variety of function-rich technology solutions. To gain maximum benefit the department must change processes and empower its staff, many of whom have really operated as administrators while agencies completed large parts of even the routine work. To successfully make this transition requires careful planning and execution of the change management process. This was emphasized in every case study reported at the MOM/DAM Symposium. Delegates repeatedly reported that to succeed you need to manage People \& Process first and only then the Technology. Further, the successful paradigm is not to see technology as a one-off introduction. What is needed is a continuous process improvement journey to better support marketing and empower the marketing staff.

PIPC's Lean Marketing Practice is providing support to a growing number of clients who are determined to move to the new marketing era using specialist to help them to improve best practice and processes, empower their staff and introduce new technology with minimal disruption to their business.

The result will be a Lean marketing capability where best practice and optimally efficient process, will be the norm, all supported by the right information technology. Merely installing the technology and subsequently adapting to the system will not deliver the benefits needed by most companies.

\section{LEAN AND ACRONYMS}

And one final thought for the CMO. When discussing your vision for your organization's 
marketing department with your CEO, it is easier to build on the successful track record of Lean rather than getting lost in the jargon of DAM, MOM, MAM, MRM, EMM, EMP. For your CEO, Lean is good.

The dawn of Lean marketing is breaking.

\section{References}

1 Womak, J. P. and Jones, D. T. (1991) The Machine that Changed the World. The Story of Lean Production. Harper Perennial, NewYork, USA.

2 Womak, J. P. and Jones, D. T. (1998) Lean Thinking. Banish waste and create wealth in your Corporation. Harper Perennial, New York, USA, ISBN 0-74324927-5.

3 Details of VE, TQM and Six Sigma can be found at.http://en.wikipedia.org/wiki/Value_engineering. The_Origins_of_Value_Engineering, http://en. wikipedia.org/wiki/TQM, http://en.wikipedia.org/ wiki/Six_sigma.

4 Lean blog. http://kanban.blogspot.com/2005/05/ what-is-lean.html.
5 PIPC Survey may be viewed at:. http://www. mrm-explained.com/MRM/conferences-papers.htm.

6 Case studies and papers on improvements gained from DAMs can be downloaded from. www. damusers,com/opa_amster06.asp, Market segmentation can be downloaded from. http:// www.claritas.com/claritas/Default.jsp?ci= $2 \& p n=$ casestudies.

7 Case studies from the Amsterdam symposium can be downloaded from: www.damusers.com/opa amster06.asp, http://www.scottish-enterprise.com/ publications/database_marketing_-enterprise_ approach_to_mrm_v050812.doc (Specific to Scottish Enterprise).

8 Magnet Harlequin. view www.magharl.co.uk.

9 Winterberry Group research at. http://www.clickz. com $/$ showPage.html?page $=3579096$.

10 Probably a cynical response born out by limited research.

11 Aprimo website: www.aprimo.com.

12 Assetlink website: www.assetlink.com.

13 Alterian website: www.alterian.co.uk.

14 Nvigorate website: www.nvigorate.com. 